\title{
Reflexões sobre a política habitacional: estado e conflitos de classes
}

\author{
Angela Michele Suave ${ }^{1}$ \\ https://orcid.org/0000-0002-2927-3438
}

\author{
Lindamar Alves Faermann ${ }^{2}$ \\ https://orcid.org/0000-0002-1622-6202
}

${ }^{1}$ Universidade de Taubaté, Programa de Mestrado em Desenvolvimento Humano, Departamento de Serviço Social, Taubaté, SP, Brasil

${ }^{2}$ Universidade de Taubaté, Departamento de Serviço Social, Taubaté, SP, Brasil

\section{Reflexões sobre a política habitacional: estado e conflitos de classes}

Resumo: O presente artigo tem como objetivo evidenciar os traços presentes na política habitacional no contexto dos governos petistas e seus influxos na vida dos trabalhadores, assim como as regressões atuais nesse setor no governo Bolsonaro, tendo como centralidade para essa análise a crise mundial do capital e suas particularidades contemporâneas, o papel do Estado na sociedade burguesa e os conflitos de classes. Para tal, considerou-se o contexto brasileiro de ofensiva ultraliberal e conservadora expresso nas contrarreformas das políticas e das ações governamentais reacionárias. Do ponto de vista metodológico, foi usada a pesquisa bibliográfica para elucidar a questão debatida. Como resultado relevante, constatou-se a importância da organização sociopolítica dos trabalhadores que, por meio dos movimentos sociais e de suas lutas cotidianas, imprimem forças para o acesso aos seus direitos, notadamente o da moradia. Nessa direção, foi essencial discutir o direito à cidade nas relações contraditórias da sociedade capitalista e os limites da democracia.

Palavras-chave: Política habitacional. Conflitos de classe. Direito à cidade. Estado. Crise capitalista.

\section{Reflections about housing policy: state and class conflicts}

Abstract: This article aims to highlight the features present in housing policy in the context of PT governments and their influence on the workers lives as well as the current returns in this sector under the Bolsonaro government, having as centrality for this analysis the global crisis of capital and its contemporary peculiarities, the role of the State in bourgeois society and class conflicts. To this end, it was consider the Brazilian context of ultraliberal and conservative offensive expressed in the government reactionary counter-reforms, policies and actions. From methodological point of view was used the bibliographical research to clarify a debated issue. As a relevant result, the importance of the socio-political organization of workers was found, which, through social movements and their daily struggles, impress forces for access to their rights, notably that of housing. In this direction, it was essential to discuss the right to the city in the contradictory relations of capitalist society and the limits of democracy.

Keywords: Housing policy. Class conflicts. Right to the city. State. Capitalist crisis.

Recebido em 31.10.2019. Aprovado em 11.02.2019. Revisado em 31.03.2019

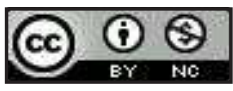

(C) O(s) Autor(es). 2020 Acesso Aberto Esta obra está licenciada sob os termos da Licença Creative Commons

Atribuição-NãoComercial 4.0 Internacional (https://creativecommons.org/licenses/by-nc/4.0/deed.pt_BR), que permite copiar, distribuir e reproduzir em qualquer meio, bem como adaptar, transformar e criar a partir deste material, desde que para fins não comerciais e que você forneça o devido crédito aos autores e a fonte, insira um link para a Licença Creative Commons e indique se mudanças foram feitas. 


\section{Introdução}

Este artigo traz reflexões sobre a política habitacional no contexto dos governos petistas (2003-2016) e elucida as particularidades de suas gestões, bem como algumas medidas regressivas adotadas pelo atual governo Bolsonaro (2019) no tocante a essa política.

Para essa discussão foi necessário contextualizar a crise mundial do capital, aproximando-se de seus traços contemporâneos e demarcando o papel do Estado no que toca à manutenção dos interesses burgueses e aos conflitos de classes, decorrentes das desigualdades que compõem a sociedade capitalista e que atravessam o cotidiano de vida dos trabalhadores. Assim, diante da reiterada violação dos direitos sociais no Brasil e nesta discussão em especial, do direito à moradia e, de forma mais abrangente, do direito à cidade, pontuam-se os limites da democracia em uma sociedade de classes, cujo acesso a essa necessidade é restringido ou negado, ocasionando os conflitos sociais.

A análise dos conflitos por moradia para a conquista do direito à cidade na atualidade brasileira é fundamental para a compreensão da realidade urbana, pois é nesse espaço que os sujeitos expropriados dos meios de produção constroem a sua trajetória e convivem com os expropriadores. Ainda, é nesse mesmo espaço que se particularizam as relações determinadas pelo sistema capitalista e se institui a luta de classes. Nesse sentido, considerou-se a cidade como um lugar de mediação da produção e reprodução social da sociabilidade humana.

Para a condução deste artigo foi usada a pesquisa bibliográfica com autores clássicos que versam sobre as relações capitalistas, o Estado e a luta social e política dos trabalhadores, como Luxemburgo (2010), Marx (2009) e Trotsky (2004). Para discutir a categoria do direito à cidade, apoiou-se em Lefebvre (2001, 2008), além de recorrer a outros autores contemporâneos que estudam moradia, espaço urbano e democracia sob a perspectiva teórico-metodológica crítica.

Dessa forma, apoiou-se no método dialético para alcançar as relações de totalidade, no sentido de aprofundar as reflexões acerca do objeto pesquisado em suas determinações mais amplas advindas das relações capitalistas. Logo, se considerou as especificidades da sociedade dividida em classes, que tem por base a exploração do trabalho e a propriedade privada, sendo atravessada pelas relações de dominação, alienação, conflitos e resistências.

Fica evidente neste artigo que a resistência e a ação dos trabalhadores se tornaram um problema para os interesses burgueses que buscam ampliar seus lucros e que, nessa fase do capitalismo, não podem mais fazer concessões. Para conter esses conflitos, o Estado cumpre fielmente sua função, pois como bem lembra Mascaro (2013), a forma política estatal é a forma do capital. Por isso, existe para garantir a exploração e a opressão dos trabalhadores, usando, para isso, métodos de conciliação e/ou de violência. Nesses termos, a modulação da democracia cessa no capital.

Diante desse cenário, é necessário resistir por meio dos movimentos sociais, das lutas e dos embates cotidianos para avançar na consciência de classe e impulsionar o direito à cidade por meio da organização social e política dos trabalhadores, pois "mesmo na noite mais triste em tempo de servidão há sempre alguém que resiste, há sempre alguém que diz não” (ALEGRE, 1965).

\section{Política habitacional: faces dos governos petistas e tendências do governo Bolsonaro no contexto da crise do capitalismo contemporâneo}

Para uma análise da política habitacional e dos conflitos por moradia para a conquista do direito à cidade, é importante considerar os elementos da crise mundial capitalista, as relações forjadas no capitalismo contemporâneo e as suas incidências na realidade brasileira e no conjunto da vida dos trabalhadores.

Pelo limite textual, resgata-se o período dos governos petistas (2003-2016), que tiveram uma "face progressista" quanto às políticas direcionadas ao conjunto de trabalhadores, e as imposições e as tendências regressivas adotadas no governo Bolsonaro no tocante à política habitacional.

Inicialmente é oportuno evidenciar que, para Lefebvre (2008, p. 13), o direito à cidade é o direito à vida urbana, com a condição de um humanismo e de uma democracia renovada. A compreensão teórica da sociedade urbana apresentada pelo autor refere-se à sociedade que nasce da industrialização, constituída por um processo que absorve a produção agrícola em um bojo em que "explodem as antigas formas urbanas, herdadas de transformações descontínuas".

A discussão sobre o direito à cidade provocada pelo autor surge como crítica aos políticos, aos urbanistas e à própria sociedade quanto à alienação ocasionada pelos imperativos de uma urbanização desenfreada e regulatória, objetivando com isso uma reflexão da cidade como espaço de encontro e de simultaneidade. Tal ideia é reforçada por Lefebvre (2001, p. 117) ao afirmar que "o direito à cidade não 
pode ser concebido como um simples direito de visita ou de retorno às cidades tradicionais. Só pode ser formulado como direito à vida urbana transformada, renovada". Para ele, as ruas da cidade são tomadas pela lógica da mercadoria em benefício do rendimento e do lucro, em que prevalece o valor de troca e não o de uso - este que é débil, alienado e alienante.

A evidência dessa lógica fica explícita nas desocupações atuais dos centros urbanos e na valorização de terrenos em forma de mercadoria, dando lugar ao lucro em detrimento das necessidades sociais e básicas dos sujeitos. A especulação do mercado imobiliário e as possibilidades de lucro sobrepõem-se ao acesso à moradia e à cidade. Dessa forma, as ocupações organizadas por movimentos sociais significam uma força política nas cidades e constituem parte da reprodução das relações, reafirmando a tese de Lefebvre (2008) de que a realidade urbana ultrapassa o campo da distribuição e intervém diretamente na produção e nas relações de produção.

Nesse sentido, entende-se a cidade contemporânea como um espaço de dominação política, econômica, cultural e social de uma classe sobre a outra, acumulando-se os problemas advindos da desigualdade gerada pela divisão social do trabalho e da riqueza. O autor sinalizou que, em seu processo contraditório, a cidade serve à formação do capital, à realização e à distribuição da mais-valia; portanto se, por um lado, funciona como uma empresa, por outro a ultrapassa em forma de reencontro com a comunidade, quando the são impostas suas necessidades.

Contudo, como pensar na cidade sob esse aspecto se nela tem se legitimado muito mais o desencontro e a violação dos direitos humanos e do direito à própria vida? $\mathrm{O}$ contexto de crise mundial do capital tem acirrado as contradições urbanas e afetado a governabilidade do capital.

Nas análises de Mota (2012, p. 29), a crise que se iniciou nos anos 1970 se mostrou a mais profunda do sistema capitalista, expondo que as contradições da acumulação se manifestaram em diferentes frentes: "a financeira, a ambiental, a urbana e a do emprego". De acordo com a autora, as alternativas encontradas pelos capitalistas para enfrentar essa crise compõem um projeto classista por uma direção restauradora que cria e reinventa iniciativas conservadoras sob o influxo das ideias liberais. É nesse sentido que essas alternativas adentraram e adentram as políticas sociais, materializando-se na vida dos trabalhadores que necessitam suprir suas necessidades mais básicas, como, por exemplo, a da moradia.

No Brasil, a contrarreforma do Estado realizada nos anos de 1990 expressou parte dessas alternativas, e foi orquestrada pelo capitalismo financeiro mundializado, devido ao seu predomínio econômico-político. Para Mota (2012, p. 33), esse projeto se expressou na "generalizada privatização do Estado com a venda de empresas estatais, e mercantilização dos serviços públicos e a redução dos benefícios da seguridade social, ao tempo em que oportunizava a financeirização do capital".

Na leitura de Castelo (2012), essa crise que ameaçou a hegemonia neoliberal em meados dos anos 1990 desencadeou uma revisão ideológica do neoliberalismo, denominada social-liberalismo, que se trata de uma tentativa político-ideológica de responder às tensões da luta de classes. Centralmente, o autor explica que, para os intelectuais do social-liberalismo, o mercado permanece a melhor opção para organizar as relações de produção; porém, devem-se ocorrer mudanças em suas principais falhas materializadas na má distribuição de renda e na destruição ambiental.

O autor tratou das particularidades do social-liberalismo no Brasil, postulando os principais conceitos da ideologia conservadora que dá sustentação ao referido projeto, bem como os da equidade e da eficiência, com uma ênfase tecnicista e focalista para o conjunto de reformas destinadas às políticas sociais ${ }^{1}$.

A lógica do social-liberalismo por ele apontada fundamenta-se na caracterização de que a pobreza dos brasileiros tem origem na perversa desigualdade na distribuição dos recursos nacionais e das oportunidades de inclusão social. Fica evidenciado pelo autor que o modelo do social-liberalismo sintetiza múltiplos fatores para as causas da desigualdade, envolvendo aspectos relacionados aos indivíduos, à educação e à luta política, hierarquicamente.

Contudo, evidencia que essa é uma forma perversa de responsabilizar singularmente as pessoas pela desigualdade: não se alcança a gênese da desigualdade que tem como base a apropriação privada das riquezas socialmente produzidas, mas sim a escolarização dada aos sujeitos, que devem buscar sair da condição de pobreza que vivem. Assim, tira-se a centralidade do trabalho e da luta de classes para focalizar na política educacional como formalidade de investimento no "capital humano", instigando a capacidade de competitividade no mercado de trabalho, além de ter como justificativa para essa saída o apoio ao microcrédito.

Seguindo esse princípio de responsabilização dos sujeitos pobres e trabalhadores, Castelo (2012) pontua as medidas sociais-liberais e as suas proposições políticas e analíticas para o combate à pobreza: prioridade e focalização dos gastos públicos nas camadas mais pobres da sociedade; integração e coordenação dos programas sociais em todos os níveis do governo e do setor privado; flexibilidade nas ações de combate à pobreza, adaptando-se às necessidades locais dos municípios e às especificidades das regiões; e aumento do grau de cooperação e do envolvimento das comunidades empobrecidas nos programas sociais. 
A ideologia social-liberal é mais uma vertente do neoliberalismo para a tentativa de dominação da burguesia, revestindo-se de uma aparência universal para a defesa dos pobres sem que os trabalhadores a percebam como um instrumento de manutenção do capitalismo.

O que se viu no caso brasileiro é que, nos governos petistas, essa fórmula foi hábil por um tempo para segurar os ânimos da classe trabalhadora no que diz respeito a uma luta mais ofensiva para a destruição do sistema, atendendo apenas parte das demandas de reprodução social dos segmentos mais pauperizados.

O fortalecimento do neoliberalismo do ponto de vista ideológico cooptou lideranças dos movimentos sociais e atingiu os mais diversos setores da classe trabalhadora. O Partido dos Trabalhadores (PT), com base no neoliberalismo, e combinado com princípios do social-liberalismo, executou políticas que beneficiaram a burguesia e colocou o Estado como o efetivo aparato que administra políticas focalistas de "combate à pobreza". Como expressão máxima desse intento, há o Programa Bolsa Família, além de outros programas mais diretos para a geração de lucros da burguesia com uma "aparência humanizada do capitalismo financeirizado", como o Programa Minha Casa Minha Vida.

Diante desse processo de cooptação o PT, que fez coro com a ideologia burguesa de neutralizar as lutas, não teve como base o rompimento com o capitalismo e perdeu sua identidade classista na tentativa de fundir o liberalismo do mercado com o progressismo social.

O projeto de aliança de classes abandonou possibilidades progressistas na defesa mais ampla dos direitos sociais dos trabalhadores, esvaziando, inclusive, os próprios mecanismos criados pelo PT de participação democrática, como, por exemplo, a dos conselhos populares que foram acopladas ao Estado, dentre outras medidas usadas pela via da inserção em movimentos sociais que cooptou lideranças atuantes e combativas.

As contradições concretas do social-liberalismo apa-

A efetivação da democracia àqueles que vendem a sua força de trabalho apenas se materializa como ato histórico quando puderem acessar à riqueza que eles mesmos produzem, sem a usurpação daqueles que se dizem donos de áreas privadas. receram na vida dos trabalhadores que pagaram (e pagam) pela crise capitalista com medidas de austeridade, sobretudo no governo Dilma (2011-2016), com cortes sociais e com o aumento do custo de serviços básicos, como o da energia elétrica, e com a alta da inflação. Esse aumentou prejudicou, principalmente, os setores mais empobrecidos, que mal conseguiram manter a compra de alimentos essenciais para sua vida e pagar os juros do seu endividamento.

$\mathrm{O}$ descontentamento com essa realidade teve como expressão emblemática as manifestações de Junho de 2013 que, ao mesmo tempo em que revelou o dissabor ao modo petista de governar, franqueou um novo estágio às lutas de classes no Brasil, soando, como adverte Mattos (2015), o alarme das classes dominantes e abrindo "um ponto de interrogação: valeria à pena continuar apostando na alternativa petista nas próximas eleições, ou era hora de retornarmos aos métodos de contenção mais tradicionais".

O Impeachment da ex-presidente Dilma Rousseff em 2016 e as eleições presidenciais de 2018 foram resultados desse processo, que se articularam à crise econômica brasileira no ano de 2014, às pressões do grande capital para aumentar as taxas de lucros, às lutas e às manifestações de caráter classista e conservadores de $2015^{2}$. Ainda, houve o papel da grande mídia para desqualificar o PT e, como consequência, proporcionar o repúdio da classe média ao Partido dos Trabalhadores.

Ademais, houve a investida de setores do Poder Judiciário, aliados a setores políticos com objetivos claros de interferir na vida pública do país para benefícios próprios. Isso expressa, segundo Casara (2018), o que se convencionou chamar de ativismo judicial, ou seja, a intromissão do Judiciário na política, que teve sua representação máxima na "Operação Lava Jato": uma ação que se apresentou contra a corrupção, mas que na prática operou com seletividade e não respondeu efetivamente ao que se propôs.

Os sujeitos envolvidos, bem como o Juiz Sergio Moro (atualmente Ministro da Justiça e Segurança Pública) e o Procurador da República Deltan Martinazzo Dallagnol, usaram de métodos parciais em relação aos processos contra o ex-presidente Luiz Inácio Lula da Silva e, com a sua prisão, impediram-no de ser candidato à Presidência da República no ano em 2018, impossibilitando assim a vontade popular e, em última instância, a democracia.

O plano de austeridade em relação às políticas sociais foi aprofundado no governo Temer com a aprovação da Reforma Trabalhista e da Proposta de Emenda à Constituição (PEC) 241 de 2016, transformada na emenda constitucional 95/2016, que restringiu por vinte anos os gastos públicos na área da educação, da saúde e da assistência social, e vem sendo ampliado no governo Bolsonaro. 
Está em curso a Reforma da Previdência, que, em essência, objetiva transformar o Sistema de Seguridade Social brasileiro em um sistema de capitalização, abrindo espaço ao capital especulativo. Suas proposições retiram direitos dos trabalhadores mediante o aumento no tempo de serviço e na contribuição para a aposentadoria; a redução da pensão por morte; a diminuição do valor do Benefício de Prestação Continuada destinado aos idosos e deficientes em situação de pobreza; dentre outros pontos que configuram ataques aos direitos sociais.

Para atender as pautas do liberalismo, outras medidas também foram tomadas pelo governo, como a extinção dos ministérios do Trabalho, Cultura, Cidades, Esportes e Integração Racial; a apresentação da Medida Provisória ${ }^{\circ}$ 881, que flexibilizou ainda mais as relações de trabalho; a criação da Secretaria das Privatizações que visa privatizar o patrimônio público, envolvendo setores do transporte e segmentos estratégicos para a economia; os cortes em programas sociais, incluindo o Programa Minha Casa Minha Vida; os contingenciamentos em Saúde e em Educação; além das mudanças na política ambiental que comprometem a fiscalização e a prevenção do desmatamento e possibilitam a liberação de agrotóxicos ao agronegócio.

No governo Bolsonaro, a pauta liberal se acentua com políticas conservadoras e militaristas. Para Moraes (2019, p. 39), há diversas interpretações a esse respeito, e algumas "discernem um fator de equilíbrio num governo composto de ultraliberais entreguistas, vociferantes criptofascistas e talibãs evangélicos". Outras análises caminham pela consideração de que há ocupação de poder pelas Forças Armadas. Assim, a forte presença militar visa estabilizar um regime de direita, ainda que necessite o uso da força e de traços autoritários, como o governo tem apresentado em diversas ações.

Essa direção política, moral e militarista constituída pela presença de militares, conservadores e liberais no governo Bolsonaro tem colocado em evidência o tema da democracia no Brasil, tendo expressão máxima em algumas narrativas que deturpam a história brasileira e chegam a negar que houve uma ditadura militar (1964-1985) no País. O depoimento do Presidente Jair Bolsonaro à TV Bandeirantes em março de 2019 é um dos indicativos desse desvario:

Temos de conhecer a verdade. Não quer dizer que foi uma maravilha, não foi uma maravilha regime nenhum. Qual casamento é uma maravilha? De vez em quando tem um probleminha, é coisa rara um casal não ter problema, tá certo? [...] E onde você viu uma ditadura entregar para a oposição de forma pacífica o governo? Só no Brasil. Então, não houve ditadura. (VEJA..., 2019).

São inúmeras as propostas e as narrativas do governo Bolsonaro, além dos escândalos que envolvem seus aliados e familiares e que caracterizam o autoritarismo e o despotismo presentes no Congresso Nacional. Essa realidade convoca os trabalhadores urgentemente à organização das lutas sociais. O que se assiste é a alteração de um Estado Social, que deveria assegurar direitos, para um Estado Penal, alicerçado na proposta vigente de militarização da vida social. A criminalização dos movimentos sociais e da população pobre e da periferia tornouse corriqueira nos dias atuais. Nesses termos, fica evidenciada a necessidade de pensarmos como as relações dos movimentos sociais por moradia estão lidando para a garantia da democracia em sua luta no território urbano.

\section{A democracia e a luta por moradia no território urbano}

Do ponto de vista da democracia burguesa e do espaço para as lutas por moradia na realidade brasileira, é importante elencar alguns elementos que retratam a luta dos trabalhadores que se organizam em movimentos sociais por habitação.

Prioritariamente, é importante considerar os sujeitos em sua condição real de vida, ou seja, numa condição de trabalhadores e de produtores que estão à procura de fazer valer o seu direito de acesso à riqueza socialmente produzida. Portanto, é fundamental entender que a ação política dos sujeitos que ocupam um terreno é advinda de uma relação de exploração que os priva do acesso ao produto que eles mesmos produzem, e não uma vontade autônoma e isolada das relações sociais estabelecidas.

Assim, a democracia para os trabalhadores já é tolhida quando vendem sua força de trabalho por não terem acesso aos meios de produção. Logo, não há democracia possível para os sujeitos que não estiverem em condições de adquirir alimentos, moradia, vestuário, saúde e educação.

Aos que compreendem que vivemos em uma democracia, sinaliza-se que prevalece a abstração, que serve para beneficiar os donos da propriedade privada. A efetivação da democracia àqueles que vendem a sua força de trabalho apenas se materializa como ato histórico quando puderem acessar à riqueza que eles mesmos produzem, sem a usurpação daqueles que se dizem donos de áreas privadas. Esses que o fazem pela posição que ocupam na divisão social do trabalho na sociedade capitalista, calcada na desigualdade da repartição da riqueza socialmente produzida. 
A apropriação privada da riqueza distancia os sujeitos dos interesses coletivos e os tornam existentes apenas num plano abstrato, como se o Estado se autonomizasse desses conflitos das relações de trabalho para almejar uma democracia para todos e universalizasse os interesses coletivos. Marx e Engels (2009, p. 47) denominam as lutas que ocorrem no interior do Estado como ilusórias, dentre elas a luta por democracia, pois "não são tratadas as lutas reais das diferentes classes entre si".

Dessa feita, a compreensão de que se vive em uma democracia na sociedade capitalista passa a ser uma alienação, pois não alcança a totalidade das relações de produção. Os próprios trabalhadores, quando reproduzem abstratamente essa ideologia da democracia, não a vivem em sua vida concreta. Não há condições materiais para a escolha e para a liberdade dos trabalhadores expressarem seus sentimentos, vontades e acessarem suas necessidades sem a abolição da propriedade privada. Nesse sistema os trabalhadores permanecerão escravizados sob um poder que lhes é alienado. Portanto, é imprescindível entender que vivemos em uma democracia burguesa, cujo limite é dado pelos capitalistas. Sob essa lógica, Chauí (2000, p. 558) esclarece que a "democracia liberal" é

[...] uma ideologia política e justifica a crítica que lhe dirigiu Marx ao referir-se ao formalismo jurídico que preside a ideia de direitos do cidadão. Em outras palavras, desde a Revolução Francesa de 1789, essa democracia declara os direitos universais do homem e do cidadão, mas a sociedade está estruturada de tal maneira que tais direitos não podem existir concretamente para a maioria da população. A democracia é formal, não é concreta.

Frente ao exposto, vale ressaltar que a tão almejada e defendida propriedade privada pelo "Estado Democrático de Direitos" só foi alcançada em sua história pela violência, guerra, pilhagem e rapinagem sangrenta. Nesses moldes, a democracia defendida pelo Estado passa essencialmente pelo atendimento dos interesses capitalistas, com parcas concessões aos trabalhadores.

Como o Estado é a forma em que os indivíduos de uma classe dominante fazem valer os seus interesses comuns e se condensa toda a sociedade civil de uma época, segue-se que todas as instituições comuns [...] que adquirem uma forma política são mediadas pelo Estado. Daí a ilusão de que a lei assentaria na vontade e, mais ainda, na vontade dissociada da sua base real na vontade livre. Do mesmo modo o direito é, por sua vez, reduzido à lei. (MARX; ENGELS, 2009, p. 112).

Com efeito, a organização sociopolítica dos movimentos sociais por moradia, que ultrapassa o campo da lei burguesa e das ideias abstratas, sinaliza um passo importante na tomada de consciência; uma aproximação perspicaz de sua atividade material no intercâmbio com outros homens. "A consciência nunca pode ser outra coisa senão o ser consciente, e o ser dos homens é o seu processo real de vida" (MARX; ENGELS, 2009, p. 31).

Contudo, é importante considerar que as lutas dos movimentos sociais transcorrem por um período de esgotamento da social-democracia, colocando-se a necessidade de superar as reformas democráticas, como as que ocorreram no período de crescimento capitalista nos países centrais. Hoje, as tarefas democráticas devem ser superadas pelos movimentos sociais de trabalhadores com vistas ao alcance de uma transformação social e política, como já dizia Trotsky:

É necessário ajudar as massas, no processo de suas lutas cotidianas, a encontrar a ponte entre suas reivindicações atuais e o programa da Revolução socialista. Essa ponte deve consistir em um sistema de reivindicações transitórias que parta das atuais condições e da consciência de largas camadas da classe operária e conduza, invariavelmente, a uma só e mesma conclusão: a conquista do poder pelo proletariado (TROTSKY, 2004, p. 13).

Com essa base trazida por Trotsky (2004) fica claro que a condução da luta por moradia para o alcance do direito à cidade não deve ser transportada de maneira separada em seu programa de reivindicações - com os limites das reformas colocados pela sociedade burguesa -, mas sim deve ser usada como mediação para alcançar a substituição desse sistema. Por isso, discutir moradia pressupõe discutir a cidade, e discutir a cidade pressupõe pensar em uma cidade para os trabalhadores, o que só é possível com a superação do próprio capitalismo, que pensa a cidade para a burguesia.

Aos trabalhadores cabe-lhes lutar contra o peso da crise que lhe é atribuída pelos capitalistas: desemprego, fome, miséria, alta dos juros, inflação, violência, desigualdade, pobreza, falta de moradia, de educação e de saúde, precariedade do transporte, crimes ambientais, dentre tantas outras demandas 
presentes no seu cotidiano. Portanto, a agonia capitalista deve ser devolvida aos burgueses, pois se "o capitalismo é incapaz de satisfazer as reivindicações que surgem dos males que ele mesmo engendrou, que morra!" (TROTSKY, 2004, p. 16).

É importante destacar que os movimentos sociais por moradia e pela cidade colocam em destaque reivindicações que alcançam um nível político, pois estão atuando diametralmente com o aparato estatal na disputa de poder político. Entretanto, essas nem sempre vêm constituídas de um caráter classista do ponto de vista da consciência dos sujeitos que se organizam pelos movimentos sociais e daqueles que vivem na cidade, ainda que pertençam efetivamente à classe trabalhadora.

O alcance da consciência de classe pelos trabalhadores pode significar um avanço em sua organização se combinado com ações políticas que expressem teorias e práticas transformadoras. Por outro lado, esse processo não é linear e vem atravessado de diversas contradições e interferências da ideologia burguesa. Tal ideologia que, por sua vez, é carregada de preconceitos e criminaliza os movimentos sociais, sendo necessário um combate cotidiano e consciente a essa interferência.

Diante da atual conjuntura brasileira, é essencial salientar que as situações de conflitos urbanos que envolvem a luta pela moradia tendem a piorar com a proposta de cortes no orçamento do principal programa habitacional para 2020, o Programa Minha Casa Minha Vida.

A luta por moradia popular sofreu dois duros golpes na última semana. O primeiro foi o cancelamento de duas portarias que previam a destinação de verbas federais para a construção de 35 mil unidades habitacionais no país todo. O segundo veio com a Proposta de Lei Orçamentária (PLOA) de 2020, encaminhada pelo governo para o Congresso Nacional. Ela prevê a redução de $41 \%$ nas verbas do programa 'Minha Casa, Minha Vida' (MCMV), o que equivale a um corte de R\$ 1,9 bilhão. (GOVERNO..., 2019)

Como uma forma de compensação a esse corte, o governo Bolsonaro propõe assegurar ao setor mais empobrecido (famílias com renda de até 1,2 mil mensais), de municípios com até 50 mil habitantes, uma espécie de crédito que comprova o pagamento e dá direito à compra do imóvel chamado de "Voucher". Isso significa a mercantilização da política e do direito social. Paralelamente significa que os grandes centros urbanos, como São Paulo, que representam expressiva parte populacional, ficarão de fora desse projeto - o que foi frisado pelo atual Ministro do Desenvolvimento Regional, Gustavo Canuto ${ }^{3}$.

Nos grandes centros urbanos o despejo dos trabalhadores passou a ser regra para aqueles que vivem em áreas ocupadas; ainda que, do ponto de vista jurídico, tenham-se criado instrumentos para fazer valer os direitos sociais. Um exemplo desses instrumentos é o Estatuto da Cidade, que se instituiu sob a premissa de regulamentar os artigos 182 e 183 da Constituição Federal, além de estabelecer diretrizes gerais da política urbana e normas de interesse social para regular o uso da propriedade em benefício do "bem coletivo".

Contudo, os dados recentes do Observatório das Remoções junho de 2019, mostram um cenário adverso ao anunciado pelo Estatuto da Cidade. De acordo com o relatório no período de dois anos e meio de pesquisa, 28.228 famílias foram removidas e 170.177 famílias estão ameaçadas de remoção, sendo que a maior parte desses casos estão localizadas no extremo Sul de São Paulo (21\%), seguido do extremo Leste (16\%) e da região do ABC (12\%). 127 das ocupações removidas ou ameaçadas tem a presença de movimentos de moradia. (EM..., 2019)

É notório que o Estado intervém nos impasses para a reprodução capitalista em meio aos ciclos de suas crises para a manutenção dos seus lucros, socializando suas perdas com os trabalhadores. Porém, o que se observa na realidade é que o Estado brasileiro não está efetivando os direitos dos trabalhadores, como previsto nas legislações, e acaba promovendo ações violentas na remoção das famílias de suas moradias, constituindo um cotidiano de instabilidade na vida de homens, mulheres, crianças e idosos. Dessa forma, o aparato estatal coloca-se como um órgão repressor contra aqueles que resistem em suas lutas.

A materialização das políticas governamentais que se efetiva pela via dos programas sociais de moradia passa, prioritariamente, pela interlocução direta com os poderes executivos dos municípios e do Estado e com o setor empresarial da construção civil. Esse processo não prioriza as demandas dos sujeitos que compõem os movimentos sociais de trabalhadores por moradia.

A luta pelo direito à moradia é fortemente influenciada pela ofensiva da especulação do mercado imobiliário e pela supervalorização dos terrenos. O principal objetivo dos setores burgueses é a geração de lucros. No entanto, esse processo também acirra os conflitos da luta pela terra com setores da classe trabalhadora que reivindicam o direito à moradia.

Ainda que o governo acene para o combate à especulação do mercado imobiliário, o que se contradiz com o projeto liberal de mercado livre sem a interferência estatal, ele permanece apostando no crédito, bem como é feito no Programa Minha Casa Minha Vida. 
Após definir os municípios que serão alvo do programa, o governo enviará técnicos para fazer uma pesquisa de campo sobre o mercado imobiliário local e identificar o tipo de voucher necessário - para comprar imóvel usado, reformar ou até construir uma nova casa - e o valor. Tudo será feito "na surdina", afirma Canuto, para evitar que o movimento gere especulação imobiliária, aumentando os custos do programa e prejudicando o mercado como um todo (NOVO..., 2019).

Compreende-se que não é pela via do crédito e do consequente endividamento que os conflitos vão se atenuar no território urbano para processo de construção de uma cidade aos trabalhadores. O crédito "oferecido aos trabalhadores", na verdade, é "oferecido às grandes empreiteiras" e mascarado pela política de austeridade do governo para enfrentar a crise iniciada em 2008 pela bolha do mercado imobiliário estadunidense, que chegou ao Brasil com força em 2015 e se arrasta até os dias atuais.

A intensificação da situação de desemprego desencadeada por essa crise coloca muitos trabalhadores endividados a interromper o pagamento dos imóveis, passando então da condição da chamada "insegurança da posse" para a condição de "sem teto". As análises de Luxemburgo (2010) são elucidativas desse processo:

\begin{abstract}
Se as crises nascem, como se sabe, em consequência da contradição entre a capacidade de expansão, a tendência à expansão da produção e a capacidade de consumo restrita do mercado, o crédito é, precisamente, [...] o meio específico de pôr em evidência essa contradição sempre que possível. Antes de tudo, aumenta de forma incomensurável a capacidade de expansão da produção e constitui uma força motriz interna que a leva constantemente a ultrapassar os limites do mercado. Fere, porém, por dois lados. Depois de ter provocado a superprodução, na qualidade de fator processo de produção, não deixa por isso de destruir com segurança, durante a crise, na qualidade de fator da troca, as forças produtivas criadas às suas custas. Ao primeiro sintoma da crise, o crédito desaparece, abandona as trocas, justamente quando seria, ao contrário, indispensável, e, onde ainda se oferece, apresenta-se como inútil e sem efeito, reduzindo assim ao mínimo, durante a crise, a capacidade de consumo do mercado. (LUXEMBURGO, 2010, p. 30).
\end{abstract}

Fica evidenciado que o crédito se constitui em um meio para especulações arriscadas e agrava a crise. Assim, se não se tem acesso à moradia, que é o pilar para acessar o direito à cidade, como se garantem a mobilidade social, a saúde e a educação do trabalhador, uma vez que grande parte desses serviços está privatizada e ainda tende a sua intensificação privatizante em um mercado calcado no projeto neoliberalista? Sem mencionar, ainda, todas as necessidades objetivas e subjetivas dos trabalhadores, que ficam impossibilitados de suprilas em uma sociabilidade extremamente desigual e violadora de direitos sociais.

\title{
Considerações finais
}

Diante desse quadro de violação dos direitos sociais, os conflitos urbanos revelam que o acesso à moradia aos que necessitam de um local para viver fica cada vez mais difícil. Com base nas relações desiguais do capitalismo, sobrepõem-se a segregação de grupos que ficam privados de suas necessidades sociais, culturais, políticas e econômicas. O que se materializa é a própria perda do direito à cidade, levando os sujeitos a fazerem uso da sua força social para impulsionar a transformação das relações para soluções dos problemas urbanos que passam pela propriedade da terra e pela marginalização social e espacial.

A tomada de consciência dos trabalhadores em relação aos problemas urbanos é um elemento importante para impulsionar lutas pelo direito à cidade e para a materialização de ações dos movimentos sociais que poderão se chocar com as estruturas para a sua transformação.

Em um contexto de democracia burguesa, em que o Estado representa os interesses capitalistas e viola os direitos da maioria da população para garantir a dominação do capital, pode-se afirmar que não há Constituição Federal, Estatuto da Cidade e programas sociais que consigam empalmar um processo de acesso universal ao direito de moradia. É necessária uma mobilização social e política dos trabalhadores que dê sustentação a esses aparatos institucionais para a destruição da lógica capitalista e do próprio Estado que a sustenta.

Nesse sentido, é necessária clareza política quanto à impossibilidade de conciliar os interesses antagônicos das classes sociais, tanto para não se cair nas armadilhas de que é suficiente adotar políticas calcadas na compensação para enfrentar as desigualdades, quanto de que vivemos em uma democracia de fato. Essa, como menciona Safatle (2010), ainda não veio! 


\section{Referências}

ALEGRE, M. Praça da Canção. Trova do Vento que Passa. [S.1.]: Dom Quixote, 1965.

CASARA, R R. R. Precisamos falar sobre a "direita jurídica”. Revista Cult, São Paulo, 10 dez. 2018. Disponível em: https:// revistacult.uol.com.br/home/direita-juridica-alem-da-lei/. Acesso em: 18 set. 2019.

CASTELO, R. O social-liberalismo brasileiro e a miséria ideológica da economia do bem-estar. In: MOTA, A. E. (org.). Desenvolvimento e construção de hegemonia: crescimento econômico e reprodução da desigualdade. São Paulo: Cortez, 2012.

CHAUÍ, M. Convite à Filosofia. 14. ed. São Paulo: Ática, 2010.

EM 2 anos e meio, mais de 28 mil famílias foram removidas na Grande São Paulo. Labcidade, 19 jul. 2019. Disponível em: http:// www.labcidade.fau.usp.br/em-2-anos-e-meio-maisde28-mil-familias-foram-removidas-na-grande-sao-paulo/. Acesso em: 24 out. 2019. GOVERNO Bolsonaro corta R \$ 1,9 bilhão do "Minha Casa, Minha Vida" para 2020. Brasil de Fato, 3 set. 2019. Disponível em: https:/ /www.brasildefato.com.br/2019/09/03/governo-bolsonaro-corta-rdollar-19-bilhao-do-minha-casa-minha-vida-para-2020/. Acesso em: 24 out. 2019.

LEFEBVRE, H. O direito à cidade. São Paulo: Centauro, 2001.

LEFEBVRE, H. A revolução urbana. Belo Horizonte: Ed. da UFMG, 2008.

LUXEMBURGO, R. Reforma ou revolução? São Paulo: Expressão Popular, 2010.

MASCARO, A. L. Estado e forma política. São Paulo: Boitempo, 2013.

MOTA, A. E. Redução da pobreza e aumento da desigualdade: um desafio teórico-político ao Serviço Social brasileiro. In: MOTA, A. E. (org.). Desenvolvimentismo e construção da hegemonia: crescimento econômico e reprodução da desigualdade. São Paulo: Cortez, 2012. MARX, K.; ENGELS, F. A ideologia Alemã. São Paulo: Expressão Popular. 2009.

MATTOS. M. B. Junho e nós: das jornadas de 2013 ao quadro atual 2015. Blog Junho, 2 jul. 2015. Não paginado. Disponível em:http:/ /blogjunho.com.br/junho-e-nos-das-jornadas-de-2013-ao-quadro-atual/. Acesso em: 18 out. 2019.

MORAES, J. Q. O fator militar no governo Bolsonaro. Revista Margem Esquerda, São Paulo, n.32, p. 40-47, jan./jul. 2019.

NOVO programa de habitação dará ‘voucher' para comprar, construir ou reformar casa própria. Estadão, 16 out. 2019. Disponível em: https://economia.estadao.com.br/noticias/geral,novo-programa-de-habitacao-dara-voucher-para-comprar-construir-ou-reformar-casapropria,70003051448. Acesso em: 24 out. 2019.

SAFATLE, V. A democracia que não veio. Folha de São Paulo, 30 ago. 2010. Disponível em:https://www1.folha.uol.com.br/fsp/poder/ po3008201013.htm. Acesso em: 24 out. 2019.

TROTSKY, L. Programa de Transição. São Paulo: Instituto José Luís e Rosa Sundermann, 2004.

VEJA 10 frases polêmicas de Bolsonaro sobre o golpe de 1964 e a ditadura militar. Folha de São Paulo, 28 mar. 2019. Disponível em: https://www1.folha.uol.com.br/poder/2019/03/veja-10-frases-polemicas-de-bolsonaro-sobre-o-golpe-de-1964-e-a-ditadura-militar.shtml. Acesso em: 24 out. 2019.

\section{Notas}

1 Um exemplo da materialização desse projeto é o Programa Bolsa Família brasileiro, que focaliza sua intervenção na transferência de renda aos setores considerados miseráveis da classe trabalhadora.

2 Em março de 2015 ocorre uma das maiores manifestações da direita contra o governo Dilma, protagonizado pela cúpula do movimento "Vem Pra Rua", apoiado por artistas, jogadores, atores globais e membros de redes socais que se juntaram em prol da insígnia do combate à corrupção e em apoio a Operação Lava Jato.

3 Num momento de forte restrição de recursos, o ministro alerta que o programa foi desenhado para priorizar quem mais precisa e que as cidades com mais de 50 mil habitantes "ficarão para um segundo momento". (NOVO..., 2019).

\section{Angela Michele Suave}

michelesuave@hotmail.com

Doutorado em Serviço Social pela Pontifícia Universidade Católica de São Paulo (PUC/SP)

Professora do Programa de Mestrado em Desenvolvimento Humano e do Curso de Serviço Social da Universidade de Taubaté-SP (UNITAU)

\section{Lindamar Alves Faermann}

lindafaermann1@gmail.com

Doutorado em Serviço Social pela Pontifícia Universidade Católica de São Paulo (PUC/SP)

Assistente Social do Tribunal de Justiça do Estado de São Paulo

Professora da Universidade de Taubaté-SP (UNITAU) 


\section{UNITAU}

Rua Visconde do Rio Branco, 22 - Centro

Taubaté, São Paulo - Brasil

CEP: 12020040

\section{Agradecimentos}

Não se aplica.

\section{Agência financiadora}

Não se aplica.

Contribuições das autoras

Não se aplica.
Aprovação por Comitê de Ética e consentimento para participação

Não se aplica.

\section{Consentimento para publicação}

Consentimento das autoras.

\section{Conflito de interesses}

Não há conflito de interesses. 